\title{
Alquimia das tintas naturais na construção do processo mágico na linguagem
}

\section{pictórica}

\author{
Alchemy of natural inks in the construction of the magical process in pictorial language \\ Alquimia de tintas naturales en la construcción del proceso mágico en lengua pictorial
}

Recebido: 07/03/2021 | Revisado: 13/03/2021 | Aceito: 17/03/2021 | Publicado: 23/03/2021

\author{
Andréa Honorato Noronha \\ ORCID: https://orcid.org/0000-0001-9598-8389 \\ Universidade Regional do Cariri, Brasil \\ E-mail: dea.crato@outlook.com \\ Maria Keliane Alves de Sousa \\ ORCID: https://orcid.org/0000-0003-4106-8821 \\ Universidade Regional do Cariri, Brasil \\ E-mail: kellyanealves15@hotmail.com \\ Patric Anderson Gomes da Silva \\ ORCID: https://orcid.org/0000-0002-6285-1439 \\ Universidade Regional do Cariri, Brasil \\ E-mail: patric.anderson@urca.br \\ Antonia Eliene Duarte \\ ORCID: https://orcid.org/0000-0001-5889-0518 \\ Universidade Regional do Cariri, Brasil \\ E-mail: antonia.duarte@urca.br \\ Ana Cláudia Lopes de Assunção \\ ORCID: https://orcid.org/0000-0001-9014-2384 \\ Universidade Regional do Cariri, Brasil \\ E-mail: ana.claudia@urca.br
}

\begin{abstract}
Resumo
O homem tem a aspiração inerente de registrar suas obras de artes desde os primórdios da antiguidade, cujo anseio levou à busca de pigmentos naturais para desenvolver tintas. Os pigmentos naturais estão presentes em toda a matéria viva e fornecem cores atraentes, em substituição aos corantes sintéticos. Nessa perspectiva, a pesquisa trata sobre os pigmentos naturais e suas possibilidades e experimentos no campo artístico, na linguagem das artes visuais, especificamente na pintura. Nesse contexto, os pigmentos tornam-se essenciais para a confecção de tintas naturais, ecológicas, podendo oferecer inúmeras possibilidades de serem transformadas em arte. $\mathrm{O}$ estudo tem por finalidade reconhecer e identificar os pigmentos naturais existentes na região do Cariri cearense. Trata-se de uma pesquisa-ação, um estudo experimental, aplicado, com abordagem exploratória e participativa, com o aporte da pesquisa bibliográfica. Sob essa égide, o material natural (mineral) foi coletado na Chapada do Araripe. Nesse caso, a coleta priorizou os subprodutos, de fácil acesso, como matéria-prima no Geossítio Riacho do Meio, Barbalha-CE. Ainda também, realizou-se a extração de matéria-prima no Lago da Misericórdia Cascata e no Parque Estadual Sitio Fundão situados em Crato-CE. É possível pensar arte desenvolvendo a sensibilidade, reconhecendo arte como conhecimento, pesquisa e criação artística, bem como, utilizar na abordagem didática nas escolas e fazer artístico dos discentes.
\end{abstract}

Palavras-chave: Tintas naturais; Arte e natureza; Educação.

\begin{abstract}
Man has an inherent aspiration to register his works of art since the dawn of antiquity, whose longing led to the search for natural pigments to develop paints. Natural pigments are present in all living matter and provide attractive colors, replacing synthetic dyes. In this perspective, the research deals with natural pigments and their possibilities and experiments in the artistic field, in the language of the visual arts, specifically in painting. In this context, pigments become essential for making natural, ecological paints, and can offer numerous possibilities to be transformed into art. The study aims to recognize and identify the natural pigments that exist in the Cariri region of Ceará. In this context, it is an action research, an experimental study, applied, with an exploratory and participatory approach, with the contribution of bibliographic research. Under this aegis, the natural material (mineral) was collected at Chapada do Araripe. In this case, the collection prioritized the by-products, easily accessible, as raw material in the Riacho do Meio Geopark, Barbalha-CE. Also, raw material was extracted at Lago da Misericórdia Cascata and at Sitio Fundão State Park located in Crato-CE. It is possible to think about art by developing sensitivity, recognizing art as knowledge, research and artistic creation, as well as using it in the didactic approach in schools and making students artistic.
\end{abstract}

Keywords: Natural paints; Art and nature; Education. 


\section{Resumen}

El hombre tiene una aspiración inherente a registrar sus obras de arte desde los albores de la antigüedad, cuyo anhelo llevó a la búsqueda de pigmentos naturales para desarrollar pinturas. Los pigmentos naturales están presentes en toda la materia viva y proporcionan colores atractivos, reemplazando a los tintes sintéticos. En esta perspectiva, la investigación aborda los pigmentos naturales y sus posibilidades y experimentos en el campo artístico, en el lenguaje de las artes visuales, específicamente en la pintura. En este contexto, los pigmentos se vuelven imprescindibles para la realización de pinturas naturales y ecológicas, y pueden ofrecer numerosas posibilidades de transformación en arte. El estudio tiene como objetivo reconocer e identificar los pigmentos naturales que existen en la región Cariri de Ceará. En este contexto, se trata de una investigación acción, un estudio experimental, aplicado, con enfoque exploratorio y participativo, con el aporte de la investigación bibliográfica. Bajo esta égida, el material natural (mineral) fue recolectado en Chapada do Araripe. En este caso, la colección priorizó los subproductos, de fácil acceso, como materia prima en el Geosite Riacho do Meio, Barbalha-CE. Además, la materia prima se extrajo en el Lago da Misericórdia Cascata y en el Parque Estatal Sitio Fundão ubicado en Crato-CE. Es posible pensar en el arte desarrollando la sensibilidad, reconociendo el arte como conocimiento, investigación y creación artística, así como utilizándolo en el enfoque didáctico en las escuelas y haciendo artísticos a los estudiantes.

Palabras clave: Pinturas naturales; Arte y naturaleza; Educación.

\section{Introdução}

Os seres humanos têm um desejo inerente de deixar sua marca na forma de obras de arte desde os tempos préhistóricos. Isso levou à busca de novos e melhores pigmentos para fazer tintas, para decorar as paredes das cavernas. Apesar da tecnologia moderna, a paleta do artista permanece uma mistura dos pigmentos usados pelos artistas das cavernas, pigmentos naturais usados na idade média e compostos orgânicos modernos (Barnett, Miller, \& Pearce, 2006)

Os pigmentos estão presentes em toda a matéria viva e fornecem cores atraentes e desempenham papéis básicos no desenvolvimento dos organismos (Kumar \& Sinha, 2004). Em vista disso, o estudo trata sobre os pigmentos naturais e suas possibilidades e experimentos no campo artístico, na linguagem das artes visuais, especificamente na pintura. Nesse cenário, os pigmentos naturais são materiais fundamentais na elaboração das tintas naturais no contexto artístico (Dias \& Candeias, 2007). Em outras palavras, os pigmentos produzem as cores que observamos em cada passo de nossas vidas, porque os pigmentos estão presentes em cada um dos organismos do mundo.

Nessa lógica, Bannach (2017) assevera que os pigmentos naturais estimas os aspectos abstratos do propósito artístico por englobar elementos sustentáveis e críticos e por envolver questões ambientais e apreciar a natureza. Em conformidade Serrano e Bannach (2015, p, 252) enfatiza que os pigmentos são categorizados de acordo com sua gênese, nesse caso, podem ser inorgânicos ou orgânicos. Os inorgânicos são aqueles extraídos da terra, por outro lado, os orgânicos são extraídos de vegetais ou animais. Desse modo Cruz (2007) esclarece que

Um pigmento é natural se é obtido diretamente da natureza, sendo apenas sujeito a processos de purificação de natureza física que permitem separar o material de que se aproveita a cor dos outros materiais a que surge associado. Atendendo a composição inorgânica dos pigmentos, é um material com origem mineral (Cruz, 2007. p.3).

O estudo busca utilizar dos pigmentos minerais e sua gama de cores obtidas das rochas arenosas e argilosas da Região do Cariri Cearense - especificamente em Crato no Parque Estadual Sítio Fundão e Cascata e também no Geossítio Riacho do Meio em Barbalha. Neste contexto, este estudo tem por finalidade investigar as origens, a classificação e manufatura dos pigmentos oriundos de fontes naturais - como os minerais - os constituintes químicos responsáveis pela produção de diferentes cores, suas atividades, durabilidade e efeitos, implementando tais estudos aos processos de ensino e aprendizagem em pintura nas escolas da Região do Cariri Cearense e demais ambientes educacionais formais e não-formais de ensino.

A efetivação deste estudo foi através da pesquisa-ação, experimentações e pesquisas realizadas com os pigmentos naturais extraídos de minerais como as rochas arenosas e argilosas encontrados no Geoparque Riacho do Meio, no Lago da 
Misericórdia Cascata e no Parque Estadual Sitio Fundão, identificando os recursos naturais possíveis de serem trabalhados e transformados, podendo ser aplicados nas aulas de Artes nas escolas da região, tendo em vista as alternativas e possibilidades do uso desses materiais de baixo custo econômico e ambiental.

O propósito desta pesquisa é adentrar no mundo de conhecimento magico, em que a arte servirá como grande estimuladora das sensações, buscando compreender as complexidades do universo, e o constante processo de transformação, da ação do homem no tempo e no espaço, as relações entre homem-espaço-natureza, possibilitando reflexões sob o uso dos recursos naturais para servir como ferramenta pedagógica. Nessa lógica, a pesquisa tem por finalidade reconhecer e identificar os recursos naturais, isto é, os pigmentos existentes na Região do Cariri Cearense, por serem materiais essenciais para a confecção de tintas naturais e ecológicas, ofertando então um universo de possibilidades pictóricas no campo artístico e educacional.

\title{
2. Metodologia
}

\subsection{Tipo de estudo, Material, Identificação e Estudos químicos}

\subsubsection{Tipo de estudo}

Trata-se de uma pesquisa-ação, um estudo experimental, aplicado, com abordagem exploratória e participativa, com o aporte da pesquisa bibliográfica. Uma das formas mais acessíveis e que podem ser realizadas com menos custos é a pesquisaação participativa (Pereira, et al., 2018). Essa metodologia foi desenvolvida por Michel Thiollent (2009). Para Tripp (2005) a pesquisa-ação é voltada para resolução de problemas nas organizações com a participação das pessoas envolvidas e a tomada de consciência de todos em relação ao que se está fazendo e por que se está fazendo alguma coisa. Neste sentido, pode-se ressaltar:

\begin{abstract}
Para resolver os problemas, seja nos ambientes de trabalho ou nas organizações, tornou-se necessária a realização de estudos e pesquisas. Um exemplo é o trabalho com deficientes visuais, ou auditivos, com problemas mentais ou outros. Durante os anos de graduação nem sempre os alunos têm como trabalhar com esse público de modo a desenvolver formas de ação eficientes e mesmo após formados, os professores precisam aprender a lidar com situações novas quando recebem alunos portadores de deficiência em suas salas de aula. $\mathrm{O}$ aprendizado de modo prático, continuado e participativo no ambiente profissional permite a professores e alunos melhorar sua formação e desenvolver uma experiência rica (Pereira et al., 2018, p. 48)
\end{abstract}

\subsubsection{Material, Técnicas de extração e avaliação da manufatura e natureza química dos pigmentos naturais}

A coleta de material natural (mineral) efetivou-se na Chapada do Araripe ${ }^{1}$. Sob essa égide, a Chapada do Araripe, é uma formação geográfica cuja delimitação percorre os estados do Ceará, Pernambuco e Piauí com extensão territorial de aproximadamente $6.066 \mathrm{~km}^{2}$. Ainda, é uma área de proteção ambiental (APA) - Floresta Nacional do Brasil, oficializada como a primeira floresta nacional em 1946. Inclui também o Geopark Araripe ${ }^{2}$ (GA) oficializado em 2016 - sob auspicio da UNESCO - como primeiro Geopark da América do Sul, integrando a Global Geopark Network (GNN) (Mochiutti, et al., 2012).

\footnotetext{
${ }^{1}$ De acordo com a Chapada do Araripe é delimitada pelas seguintes coordenadas $38^{\circ} 0^{\prime}$ e $41^{\circ} 55^{\prime}$ oeste e $70^{\circ} 10^{\prime}$ e $7^{\circ} 50$ sul.

${ }^{2}$ O Geopark Araripe é delimitado por 9 Geossitios paleontológicos alocados nos municípios de Crato (Geossítio Batateiras); em Barbalha (Geossítio Riacho do Meio); em Juazeiro do Norte (Geossitio Colina do Horto); em Nova Olinda (Geossítio Pedra Cariri e Ponte de Pedra); em Missão Velha Cachoeira de Missão Velha e Floresta Petrificada; e em Santana do Cariri (Parques dos Pterossauros e Pontal da Santa Cruz).
} 
Nessa lógica, a coleta priorizou os subprodutos, de fácil acesso, como matéria-prima. Desse modo, o processo de extração de pigmentos naturais começou a partir da aula de campo na disciplina de Pintura I³ , no Geossítio Riacho do Meio, localizado na cidade de Barbalha-CE. Ainda também, realizou-se a extração de matéria-prima na Cascata e no Parque Estadual Sitio Fundão, situados em Crato-CE.

Em síntese, é importante destacar que a coleta de material foi realizada através da técnica dos pigmentos como: o destorroamento, a pilagem, a peneiragem, o adicionamento dos aglutinantes naturais, água, e posteriormente a aplicação em lonas de algodão, papel e corpo.

\subsubsection{Oficinas de pigmentos no CAPS e Escolas Públicas da Região do Cariri}

Para a realização das oficinas no Centros de Atenção Psicossocial (CAPS), abordou-se técnicas de manufaturas dos pigmentos naturais e aplicação das tintas ecológicas nos seguintes tipos de suportes: papel, madeira e lona de algodão, respeitando a livre expressão dos participantes tudo pensado e realizado de maneira lúdica. Adicionalmente, utilizou-se da abundância, as gentilezas o afago, o carinho, os ouvidos, as palavras de incentivo e confiança e a cima de tudo o respeito (Figura 1). Nesse contexto, Serrano e Bannach (2015, p, 254) assegura que "com a experimentação permite-se as crianças, um olhar especial para o meio que vivem, proporcionando um contato com a Arte através da manipulação de materiais que seriam descartados". No tocante as escolas públicas da Região do Cariri, utilizou-se as manufaturas dos pigmentos naturais, abordagens e experimentos com os aglutinantes naturais e também, ministrou-se algumas aulas sobre história da arte conforme os livros didáticos adotados pelas escolas.

Figura 1. Oficina de pintura com Pigmentos Naturais no CAPS - Centro de Atenção Psicossocial, Crato-CE, 2019.

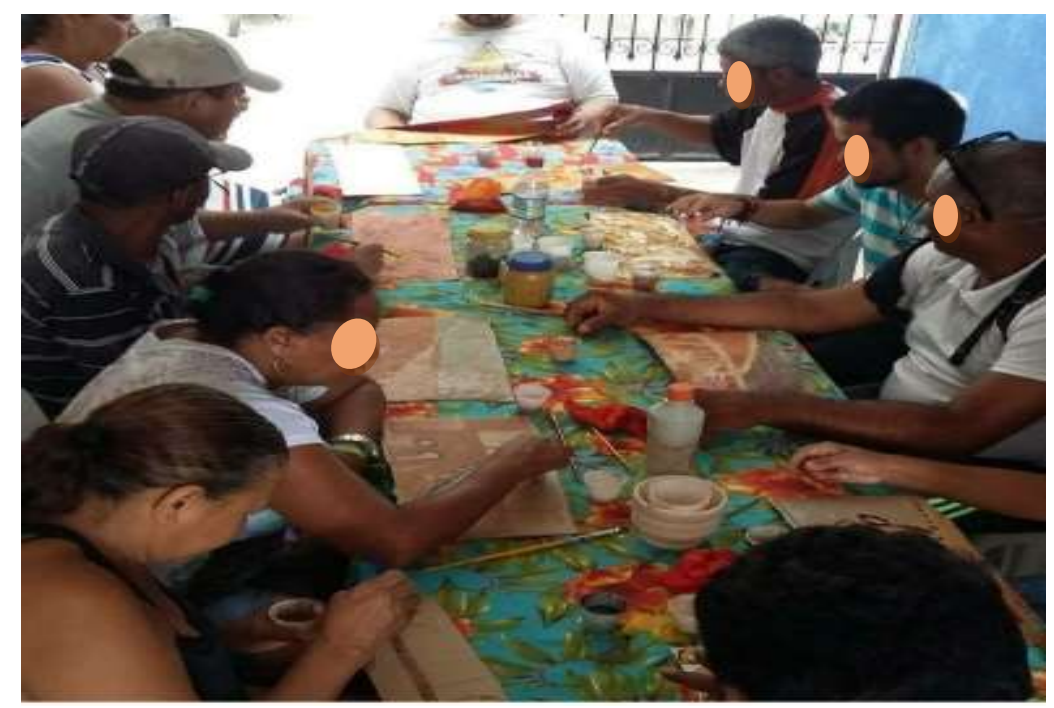

Fonte: Autores.

\subsection{Experimentos com os aglutinantes naturais}

A finalidade do aglutinante é propiciar viscosidade ao pigmento, homogeneizando as partículas do material. Conforme Rodrigues (2011) o aglutinante unifica as partículas estruturando fortes películas adesivas ao serem oxidas pelo $\mathrm{O}^{2}$ (oxigênio). Nesse caso pode-se mencionar a gema do ovo, gorduras animais, resinas e fotoassimilados de plantas, entre outros aglutinantes oriundos de produtos naturais, como exemplos (Dias e Candeias, 2007; Cruz, 2007; Rodrigues, 2011). Na

\footnotetext{
${ }^{3}$ É importante enfatizar que a atividade aconteceu sob a supervisão e coordenação da Doutora Professora Ana Cláudia Lopes de Assunção, Centro de Artes, Universidade Regional do Cariri (URCA).
} 
produção e manufatura das tintas naturais é imprescindível mensurar as proporções equivalentes de cada produto natural (de modo que evite a produção de uma tinta muito espessa ou muito fina), a fim de obter uma mistura de consistência satisfatória, cujo resultado se traduz nos trabalhos desenvolvidos.

Conforme é ilustrado na Figura 2, foram realizados outros experimentos com a gema do ovo, a Aloe Vera (Babosa), gorduras animais para extração de colágeno e, também, a gelatina como cola animal, cola de arroz, de origem vegetal e também, resinas de árvores que conforme aponta Mello e Suarez (2012) são resistentes e utilizadas com frequência na arte e cultura chinesa.

Figura 2. Experimentos com os aglutinantes naturais, ovo e Aloe Vera (Babosa).

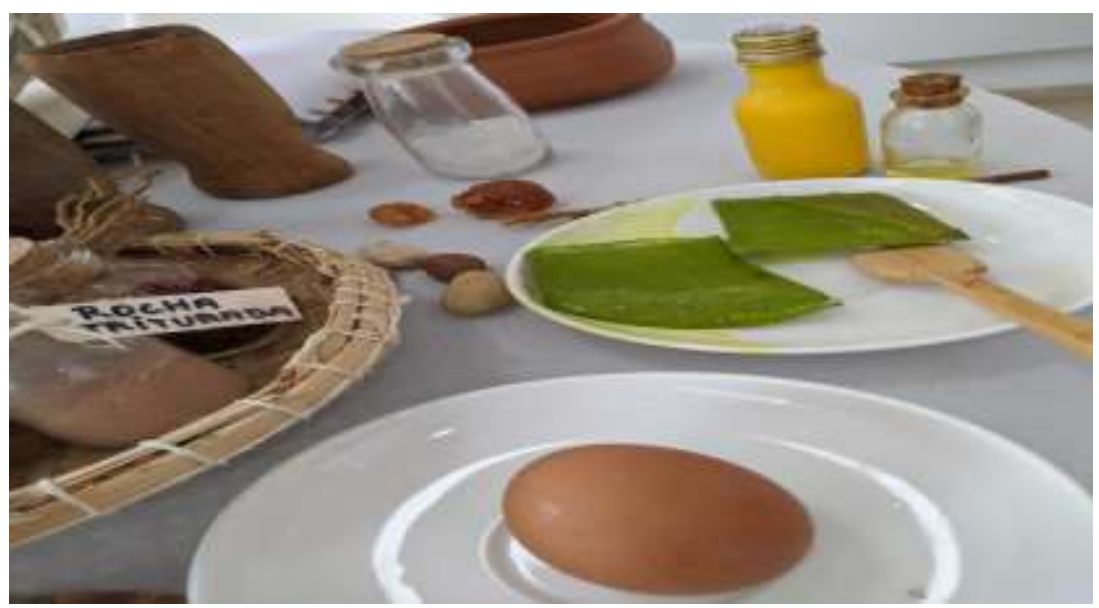

Fonte: Autores (2018).

Os minerais em sua forma natural com pigmentações distintas quando combinados com aglutinantes oriundos da natureza contrapõem contraste de tonalidades de cores naturais representam modernidade no processo pedagógico, incentivando a criatividade a sensibilidade (Rodrigues, 2011). Conforme, Silveira, Quadros, \& Silva (2020) a arte cultiva o pensamento crítico-ativo e estético no que concebe a relação espaço-homem-natureza. Nesse sentido, Ferraz e Fusari (2010, p. 17) oferece uma chave interpretativa para compreender a Educação através da Arte, desse modo, determina que

É um movimento educativo e cultural que busca a constituição de um ser humano completo, total, dentro dos moldes do pensamento idealista e democrático. Valorizando no ser humano os aspectos intelectuais, morais e estéticos, procura despertar consciência individual, harmonizada ao grupo social ao qual pertence.

\section{Resultados e Discussão}

A ausência de recursos didáticos-pedagógicos para o ensino de artes é uma realidade no ambiente escolar público (Rodrigues, 2011). Entretanto, Silva, \& Ciasca (2020) salienta que as condições efetivas docente e os recursos didáticos pedagógicos são condições sine qua non no processo educativo e formativo. Nesse contexto, transformar matéria orgânica ou inorgânica em recursos didáticos e pedagógicos, ou seja, em pigmentos, é uma alternativa na efetivação de uma aprendizagem significativa (Lima, 2018). Sob essa égide, realizou-se o processo de extração de pigmentos naturais na Chapada do Araripe, especificamente no Geossítio Riacho do Meio em Barbalha, e também no Parque Estadual Sítio Fundão e na Cascata em Crato. Nessa lógica, na etapa de extração, constatou-se a ocorrência de rochas arenosas e argilosas nas proximidades e no leito do rio, no qual possibilitou extrair os pigmentos minerais, em sua forma natural, para explorar em processos artísticos.

Os pigmentos naturais contidos nas rochas encontradas na Chapada do Araripe, constituem materiais que podem ser utilizados na sua integralidade, quanto à constituição mineral, com amplo potencial para gerar cores e tonalidades distintas. 
Nesse caso, obteve-se na Cascata e no Parque Estadual Sítio Fundão materiais argilosos e arenosos, de cores amarelo ocre, vermelho, marrom, cinza, verde, preto e branco. Por outro lado, no Geossítio Riacho do Meio obteve-se a extração de cores rosa, branco, bege e marrom.

Sendo então, utilizados na forma de grânulos mais finos e de grânulo mais grossos, conforme adaptado à proposta de trabalho. Nesse caso, o processo de construção e elaboração foi sintetizado com suporte da pesquisa e também do fazer artístico. Por exemplo, no primeiro experimento (Figura 3) produziu-se uma pintura com pigmento natural de uma matéria excessivamente triturada e peneirada, em processo repetidamente realizado, obtendo como produto um pó muito fino, a fim de atingir o objetivo da proposta que foi trabalhar com pintura sem texturas, sem ondulações na sua superfície, sem acúmulo de materiais, tornando o trabalho mais delicado.

Figura 3. Experimento pictórico sem textura em suporte lona de algodão.

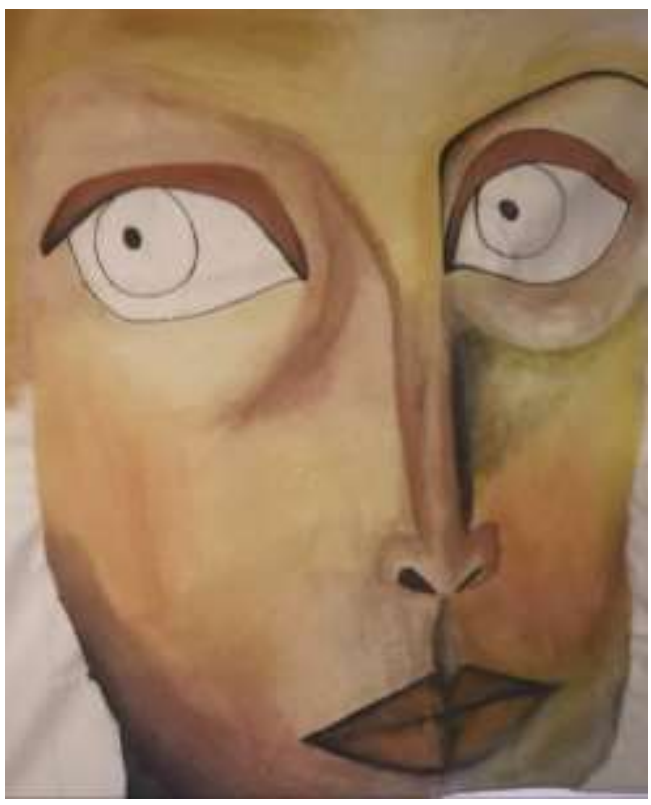

Fonte: Autores (2017).

Em contrapartida, no segundo experimento (Figura 4) elaborou-se uma pintura cheia de textura, de acúmulos, sobreposições de materiais e cores, num processo de confecção da tinta natural mais espessa, mais grossa, cheia de grânulos minerais, obtidos da consistência das rochas, do material manufaturadamente mais grosso, com o fim de que a pintura ressaltasse; neste trabalho utilizamos suporte tela de algodão.

No tocante, ao processo de construção pictórica optou-se por utilizar técnica das tintas naturais. Iniciou-se pela elaboração do suporte com lona de algodão útil para confecção do fundo do suporte com duas demãos de látex branco, deixando enxugar por completo. Em seguida, efetivou-se a manufatura das rochas arenosas e argilosas encontradas no Riacho do Meio, consequentemente, selecionou-se as cores, e deu iniciou ao processo de pilagem, peneiragem e aglutinação. 
Figura 4. Experimento pictórico com textura em suporte lona de algodão.

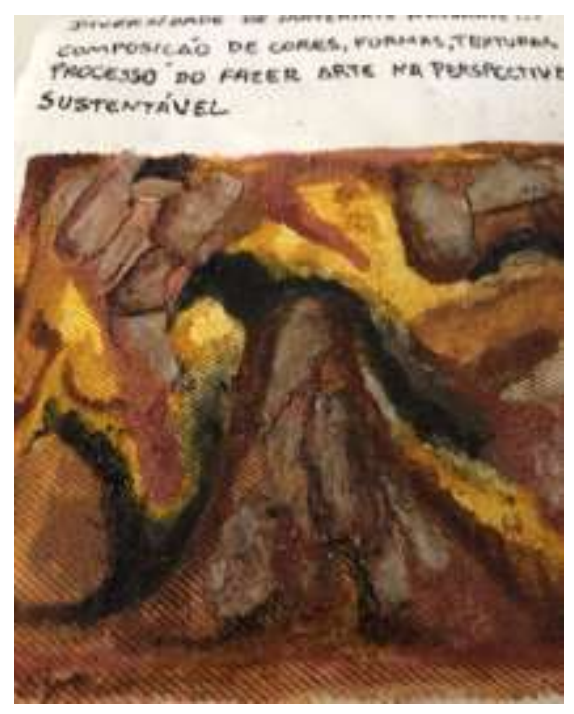

Fonte: Autores (2017).

Conforme aponta a Figura 5, realizou-se uma pintura inúmeras abstrata (figurativas, retratos, paisagens, entre outras). As obras ressaltam muita textura, formas, cores, composições elaboradas a partir dos elementos da natureza, pintura rústica, sustentável e ecológica. É perceptível o universo de possibilidades e vantagens que se pode auferir quanto ao uso dos pigmentos naturais. Nessa perspectiva, de Jesus, et al., (2018) enfatiza que, deve-se instaurar novos modos de produção de tintas, no entanto, de forma sustentável. Isto é, sem comprometer o meio ambiente e futuras gerações. O processo de como elaborar e confeccionar sua própria tinta natural auxilia na melhorar a compreensão dado que é atóxica, de fácil acesso, baixo custo ambiental e econômico, é um material abundante nesta região e pode ser utilizado para diversos fins em arte, pintura em paredes, na bioconstrução, entre outros usos.

Figura 5. Construções Pictóricas.



Fonte: Autores.

Outra grande vantagem em utilizar esses materiais na educação formal e não-formal é que podem ser manuseados por diversas faixas etárias, pois sendo atóxica e solúvel em água, não oferece riscos à saúde, mas, longe de querer, aqui, exaurir todas as possibilidades desse material. 


\section{Considerações Finais}

O desejo de sair uma marca para as gerações futuras faz parte do anseio humano que tem impulsionado a busca por pigmentos com permanência e intensidade de cor. Isto garantirá um mercado contínuo para a arte, pesquisa e para fornecer novos e melhores pigmentos.

É na mistura das misturas naturais que aprendesse, com os experimentos, alguns rituais da alquimia, pela combustão do sol, fogo, da água e do ar, elementos naturais deste universo, alimentando e alimentados pela energia natural da terra. Simples confecção e transformações de materiais, através de pesquisas, conhecimento, desenvolvimento artístico e experiências, vivendo e encantando com as possibilidades que a arte permite.

Absorvida pelas energias próprias que a natureza oferece, sente-se a necessidade deste processo com os materiais naturais, de natureza simbiótica, uma sensação de troca e interação, enquanto adentra-se com a arte na linguagem pictórica, a natureza em sua exuberância favorece o conjunto de materiais necessários à produção, manufatura e aplicação no universo artístico, realizando-se o processo da arte natureza e suas possibilidades infinitas.

Aos experimentos com as tintas naturais, para executar os trabalhos artísticos, procura-se sempre incorporar outros possíveis materiais, seja em relação ao pigmento ou nos aglutinantes e solventes, materiais todos invariavelmente naturais. Neste universo vasto e infinito que permeia o rol das riquezas naturais, a terra que pisasse é o que provoca, ampliando o conhecimento entre os saberes da arte, resultando em formas prazerosas de interessantes experimentações dos fazeres artísticos no uso dos recursos naturais, na busca por descobrir novos caminhos possíveis de aprender e ensinar arte.

O desejo de dialogar com cores que estão no mundo, provoca o sonho do artista e seus desafios é visto de um modo diferenciado de maneira sensível, reflexiva e expressiva. Através da busca por conhecimento o artista transita nas diversas áreas de conhecimento ampliando saberes, construindo arte, cultura, ciência, tornando tudo interessante, oferecendo melhor possibilidade.

O resultado desta pesquisa é fruto de uma construção de experimentos do fazer, criar, contextualizar, nos determinados processos artísticos e científicos, alquímicos, com o objetivo de alcançar todos aqueles que pretendem descobrir alternativas de trabalhos de arte por um lado sustentável, desvendando processos que queiram enriquecer experimentações em relação aos pigmentos naturais.

Tendo em vista que uma das características do Geopark Araripe é a riqueza singular, patrimonial e cultural que apresenta, isto inclui, os saberes antropológicos, culturais e científicos como: geológicos, paleontológicos, históricos, ambientais, hidrológicos, entre outros. O presente estudo serve como coordenadas para repensar em ações pedagógicas envolvendo a matéria prima de forma sustentável.

Em síntese, esta pesquisa propicia o desenvolvimento das práticas, a partir das histórias da arte, sobre os primórdios, as primeiras formas de expressar arte na terra, como as pinturas rupestres, como também revela um estudo sobre as características dos materiais e suas transformações. Deste modo é possível pensar arte e utilizar na abordagem didática nas escolas, na sala de aula com os alunos não necessariamente só para os experimentos, produções artísticas e sim para o desenvolvimento dos fazeres artísticos dos alunos. É possível pensar arte desenvolvendo a sensibilidade, reconhecendo arte como conhecimento, pesquisa e criação artística.

\section{Referências}

Alves, C. C. E., Siebra, F. S. F., Bezerra. L. M. A., Oliveira, M. L. T. (2010). Geopark Araripe: um estudo Geoturristico e a mbiental no GEOTOPE Granito, Ceará/Brasil. VI Seminário Latino Americano de Geografia Física. II Seminário Ibero Americano de Geografia Física. Universidade de Coimbra.

Bannach, C. L. (2017). Arte e natureza: o uso de pigmentos naturais na prática artística e educacional. Monografia (Graduação) - Universidade Estadal Paulista. Faculdade de Arquitetura, Artes e Comunicação, Bauru, São Paulo, Brasil. 
Research, Society and Development, v. 10, n. 3, e51110313632, 2021

(CC BY 4.0) | ISSN 2525-3409 | DOI: http://dx.doi.org/10.33448/rsd-v10i3.13632

Cruz, A. J. (2007). Os pigmentos naturais utilizados em pintura. Pigmentos e Corantes Naturais. Entre as artes e as ciências. Évora: Universidade de Évora, $5-23$

Dias, A. S., \& Candeias, A. E. (2007). Pigmentos e corantes naturais: entre as Artes e as Ciências.

de Jesus, A. B., de Freitas Silva, A., Borges, L. M., \& Ramos, T. C. (2018). Tintas do solo: análise de uma prática de ensino interdisciplinar de química e arte. ciclo Revista (ISSN 2526-8082), 3(1).

Ferrza, M. H. C. T., \& Fusari, M. F. R. (2010). Arte na educação. São Paulo: Cortez.

Kumar, J. K., \& Sinha, A. K. (2004). Resurgence of natural colourants: a holistic view. Natural product research, 18(1), 59-84.

Lima, A. V. (2018). A arte com a natureza: experimentos de pigmentos naturais na educação do campo em alternância (Bachelor's thesis, Brasil).

Mello, V. M., \& Suarez, P. A. (2012). As formulações de tintas expressivas através da história. Revista virtual de química, 4(1), 2-12.

Mochiutti, N. F., Guimarães, G. B., Moreira, J. C., Lima, F. F., \& Freitas, F. I. (2012). Os valores da geodiversidade: geossítios do Geopark Araripe/CE. Anuário do Instituto de Geociências, 35(1), 173-189.

Pereira, A. S., et al., (2018). Metodologia da pesquisa científica. Santa Maria, RS: UFSM, NTE.

Rodrigues, V. M. S. (2011). Utilização de tintas naturais em sala de aula a partir de pigmentos e aglutinantes regionais. Monografia (Licenciatura em Artes Visuais) - Universidade de Brasília, Universidade Aberta do Brasil, Brasiléia.

Serrano, E. P. G., \& Bannach, C. L. (2015). Arte e natureza: os pigmentos naturais na poética pictórica art and nature: the natural dye in pictorial poetic.

Silva, L. M. da, \& Ciasca, M. I. F. L. (2020). School physical structure as a determinant of quality in education in professional schools in Ceará: between reality and myth. Research, Society and Development, 9(7), e642974634. https://doi.org/10.33448/rsd-v9i7.4634

Silveira, R. B. da, Quadros, I. P., \& Silva, C. L. L. P. V. da. (2020). Poetic itineraries: moving around the city as a driver of aesthetic experiences in art teaching. Research, Society and Development, 9(7), e554974343. https://doi.org/10.33448/rsd-v9i7.4343

Thiollent, M. J. M. (2009). Pesquisa-ação nas organizações. São Paulo: Atlas.

Tripp, D. (2005). Pesquisa-ação: uma introdução metodológica. Educação e pesquisa, 31(3), 443-466. 